\title{
SCREENING OF CHLORAMPHENICOL RESIDUES IN CHICKENS AND FISH IN CHITTAGONG CITY OF BANGLADESH
}

\author{
M. A. Bakar*, A. J. M. Morshed, F. Islam and R. Karim ${ }^{1}$ \\ Bangladesh Council of Scientific and Industrial Research Laboratories, Chittagong, Bangladesh \\ ${ }^{1}$ Bangladesh Council of Scientific and Industrial Research, IFST, Dhaka, Bangladesh
}

\begin{abstract}
Chloramphenicol, an illegal antibiotic has been widely used in aquaculture and poultry as an anti-microbial agent which has been banned in many countries for its toxic side effects. A random screening of chloramphenicol residues in some poultry and fishes by Liquid Chromatography Tandem Mass Spectrometry (LC-MS/MS) have been carried out. The determined concentrations of chloramphenicol in farmed and wild chickens and its liver, various types of farmed fishes were in the range of minimum value of $0.133 \mu \mathrm{g} / \mathrm{kg}$ to the highest value of $0.515 \mu \mathrm{g} / \mathrm{kg}$. The lowest concentration of $0.133 \mu \mathrm{g} / \mathrm{kg}$ was determined in Pungas fish and the highest of $0.515 \mu \mathrm{g} / \mathrm{kg}$ in Rui fish. Minimum Required Performance Limit (MRPL) in food of animal origin like Meat, Eggs, Milk, Urine, Honey and Aquaculture products for Chloramphenicol is $0.3 \mu \mathrm{g} / \mathrm{kg}$. The results of eight samples out of thirteen have been exceeded the limit of MRPL. So it is a matter of great concern for us.
\end{abstract}

Key words: Chicken, Fish, Chloramphenicol, LCMSMS

\section{INTRODUCTION}

Chloramphenicol has been extensively used both in human medicine such as eye drops and topical cream and veterinary practice, due to its powerful broad spectrum antimicrobial activity as well as its remarkable penetration into the tissues. Although reasonably safe in domestic animals, however, it is known to exert many side effects in humans such as allergic reactions, gastrointestinal disorders (Mehdizadeh et al., 2010) Residues of chloramphenicol in food consumed by humans, leads to very serious bone marrow diseases and a syndrome of cyanosis and cardiovascular collapse known as "grey syndrome" may also occur, particularly in neonates. Application of chloramphenicol in reared animals is raising serious concerns due to its bioaccumulation in tissues. Presence of anti-microbial drug residues in the edible tissues can cause acquisition of drug-resistance. International bodies like Food and Agricultural Organization (FAO), World Health Organization (WHO) have already raised the issue of indiscriminately use of antibiotics in all food production sectors, with particular concern for the potential risks to human health and hence the application of chloramphenicol in food is forbidden (Raffi and Suresh, 2011). Chloramphenicol is not allowed for use in the treatment of animals for food production in the EU and may not be used in the production of food of animal origin which is imported into the EU. The use of chloramphenicol and nitrofurans in the treatment of food producing animals is prohibited in the EU and residues should be absent in food products, whether home-produced or imported, intended for human consumption.

Unfortunately chloramphenicol is freely available in Asia and is broadly used and abused for both livestock and in aquaculture. The fact that large quantities of the drug are manufactured and transported creates the possibility of cross contamination with less toxic drugs and nutrients. In the present case it is evident that ingredients incorporated in premixes were contaminated with chloramphenicol at some stage in the chain extending from production through delivery. The present study was designed with the assessment of chloramphenicol residue in chickens and fish by using Liquid Chromatography Tandem Mass Spectrometry (LCMSMS). LCMSMS is very effective technique for trace level analysis for its good selectivity, high sensitivity, fine precision and accuracy.

\section{MATERIALS AND METHODS}

Samples were carefully handled to avoid contamination. Glassware was properly cleaned, and the reagents were of analytical grade. Deionized water was used throughout the study. The techniques for sample collection, extraction, standard preparation, analysis system for chloramphenicol have been briefly described below.

\section{Sample Collection}

Three varieties of chickens and six types of fishes were collected from local market in Chittagong City, Bangladesh in September, 2013.

*Corresponding e-mail address: bakar1012@yahoo.com 


\section{A. Bakar and others}

\section{Sample Extraction}

Five gram homogenized every sample was taken in a $50 \mathrm{ml} \mathrm{ppt} \mathrm{tube.} \mathrm{Then} \mathrm{the} \mathrm{sample} \mathrm{was} \mathrm{homogenized} \mathrm{using}$ Ultraterex for $2 \mathrm{~min}$ after adding $5 \mathrm{ml}$ deionized water. After that $10 \mathrm{ml}$ ethyl acetate was added into the sample and mixed the solution by vortex mixture.

Then the sample was centrifuged for $10 \mathrm{~min}$ at $5000 \mathrm{rpm}$. Then the ethyl acetate layer was transferred to $15 \mathrm{ml}$ ppt tube and the sample was evaporated to dryness under a gentle stream of nitrogen on a heating at $55^{\circ} \mathrm{C}$. Then the residue was dissolved in $1 \mathrm{ml}$ water. After adding $1 \mathrm{ml}$ hexane the solution mixed and centrifuged for 10 minutes at $3000 \mathrm{rpm}$. Then lower phase (Water layer) was collected and filtered it through a Phenex $0.45 \mu \mathrm{m}$ filter. Then it was transferred to an auto sampler vial for LC/MS/MS analysis (Anon., 2013).

\section{Standard Preparation:}

The stock solution of Chloramphenicol was prepared in Acetonirile at 1000mg/l. The working standard solution of $0.1,0.5,1,2.5,5$ and $10 \mu \mathrm{g} / \mathrm{l}$ level for calibration curve were prepared by dilution in water on the day of analysis.

\section{LCMSMS Conditions}

Column : Phenomenex Aqua $5 \mu, \mathrm{C} 18,125 \AA, 50 \times 2 \mathrm{~mm}$

Eluent $\mathrm{A} \quad$ : Water $+0.1 \%$ formic acid $+5 \mathrm{mM}$ ammonium acetate

Eluent B : Methanol $+0.1 \%$ formic acid $+5 \mathrm{mM}$ ammonium acetate

MSMS system parameter (API-4000, AB Sciex)

\begin{tabular}{|lccccccccc|}
\hline Analyte & $\begin{array}{c}\text { MW } \\
\text { (Dalton) }\end{array}$ & Polarity & Q1 & Q2 & $\begin{array}{c}\text { DP } \\
\text { (Volts) }\end{array}$ & $\begin{array}{c}\text { EP } \\
\text { (Volts) }\end{array}$ & $\begin{array}{c}\text { CE } \\
\text { (Volts) }\end{array}$ & $\begin{array}{c}\text { CXP } \\
\text { (Volts) }\end{array}$ & $\begin{array}{c}\text { RT } \\
(\mathrm{min})\end{array}$ \\
\hline Chloramphenicol & 322 & Negative & 320.90 & 151.90 & -75.0 & -10.0 & -24.0 & -9.0 & 3.13 \\
& & & & 256.80 & -75.0 & -10.0 & -16.0 & -5.0 & 3.13 \\
\hline
\end{tabular}

Curtain gas: 30 psi, Collision gas: Medium, Ion spray voltage (volts):-4500, Temperature: $450^{\circ} \mathrm{C}$, Ion source gas (GS1): 50 psi, Ion source gas (GS2): 50 psi

\section{RESULTS AND DISCUSSION}

Three varieties of chickens and five types of fish sample were analyzed. Values of chloramphenicol concentrations in total thirteen different samples have been shown in Table 1. The determined concentrations of chloramphenicol in all kinds of meat and fish were in range from $0.133 \mu \mathrm{g} / \mathrm{kg}$ to $0.515 \mu \mathrm{g} / \mathrm{kg}$. The lowest level of chloramphenicol $(0.133 \mu \mathrm{g} / \mathrm{kg})$ was found in Pungas fish and the highest level $(0.515 \mu \mathrm{g} / \mathrm{kg})$ in Rui fish. The European Commission has recently in the Rapid Alert System for Food and Feed (RASFF) distributed several notifications concerning the presence of chloramphenicol in enzymes used in food processing and as and feed additives (Anon., 2013 ).

Table 1. The results of chloramphenicol detected in different types of samples

\begin{tabular}{|llc|}
\hline Sl. No. & Sample name & Result $(\mu \mathrm{g} / \mathrm{kg})$ \\
\hline 01 & Meat (Indigenous chicken) & 0.405 \\
02 & Meat (Broiler chicken) & 0.403 \\
03 & Meat ( ISA brown chicken) & 0.373 \\
04 & Liver (Indigenous chicken) & 0.438 \\
05 & Liver (Broiler chicken) & 0.275 \\
06 & Liver ( ISA brown chicken) & 0.250 \\
07 & Tilapia fish (Large ) & 0.406 \\
08 & Tilapia fish (Small ) & 0.301 \\
09 & Pungas fish & 0.133 \\
10 & Pungas liver & 0.167 \\
11 & Anabas fish & 0.188 \\
12 & Trout fish & 0.328 \\
13 & Rui fish & 0.515 \\
\hline
\end{tabular}


Original analysis certificate according to EU regulation, issued by Government of the Peoples Republic of Bangladesh department of Fisheries Fish Inspection and Quality Control Laboratory starting that result is not detected up to a MRPL (Minimum Required Performance Limit) of Chloramphenicol less than $0.3 \mu \mathrm{g} / \mathrm{kg}$. According to European Union commission decision that MRPL in food of animal origin such as Meat, Eggs, Milk, Urine, Honey and Aquaculture products for Chloramphenicol is $0.3 \mu \mathrm{g} / \mathrm{kg}$ (EC, 2003). The results of eight samples out of thirteen have been exceeded the limit of MRPL. Chloramphenicol was found 0.275, 0.250, 0.133, $0.167,0.188 \mu \mathrm{g} / \mathrm{kg}$ in five sample i.e liver (Broiler chicken), Liver (ISA brown chicken), Pangas fish, Pangas liver Anabas fish respectively, which comply with MPRL. But other eight sample i.e Meat (Indigenous chicken), Meat (Broiler Chicken), Trout fish, Rui fish, Liver (Indigenous chicken), Tilapia fish (Big size), Tilapia fish (Small size), Meat (ISA brown chicken) contained $0.405,0.403,0.373,0.438,0.406,0.301,0.515$ and 0.328 $\mu \mathrm{g} / \mathrm{kg}$ chloramphenicol respectively, which have overcome the limit of MPRL. So it is not good news for us to consume antibiotics contaminated foods. So many germs are being resistance for these reasons. It causes many problems in our health. Choramphenicol is a prohibited drug for used in animal food in the USA. Studies revealed that in the United States and in Europe, persistent rates of chloramphenicol resistance were found after withdrawal of the drug from therapeutic use in animals (Kenneth et al., 2005)

Low ophthalmologic doses causes aplastic anemia in human and bone marrow aplasia induced by Chloramphenicol is not dose dependent. This, together with other toxic and carcinogenic effects of chloramphenicol, has caused particular concern for the public health Many countries have banned the use of chloramphenicol in food producing animals. FDA, FAO, WHO and Expert Committee on Food Additives (JECFA) has declared that chloramphenicol residues in human food supply are unacceptable (Mehdizadeh et al., 2010)

\section{CONCLUSION}

The current study suggests a high risk of illegal use of chloramphenicol in poultry and aquaculture and strict measures should be taken in this regard. The presences of high concentration of chloramphenicol in maximum samples are alarming for the public health. This study will give a message for government body to control the proper use of antibiotics.

\section{ACKNOWLEDGEMENTS}

The authors wish to thank to director and division's personnel of BCSIR Laboratories, Chittagong, Bangladesh for being a constant source of inspiration, initiation and motivation to carry out this study.

\section{REFERENCES}

1. Anonymous (2013). Amfep statement on chloramphenicol contamination in a feed enzyme preparation. [http://www.amfep.org].

2. EC (2003). Imports of animals and food of animal origin from non-EU countries, Commission decision.181 pp-12

3. Kenneth MB, David G.W, Michael EH, Toni LP and Dabid JN (2005). The chloramphenicol resistance gene $\mathrm{cmlA}$ is disseminated on transferable plasmids that confer multiple-drug resistance in swine Escherichia coli. FEMS Microbiology Letters 243: 285-291.

4. Mehdizadeh S, Kazerani HR and Jamshidi A (2010). Screening of chloramphenicol residues in broiler chickens slaughtered in an industrial poultry abattoir in Mashhad, Iran. Iranian Journal of Veterinary Science and Technology 2(1): 25-32.

5. Raffi SM and Suresh TV (2011). Screening of Chloramphenicol in wild and cultured shrimp Penaeus monodon by Competitive Enzyme Linked Immunosorbent Assay, International Conference on Chemical, Biological and Environment Sciences (ICCEBS'2011) Bangkok. 